Submission number: 10336

Translation issues in Grounded Theory 


\title{
Translation issues in Grounded Theory
}

\begin{abstract}
This paper explores the translation and interpretation issues that arose during a grounded theory study of the Hellenic health sector. It outlines the problems that were encountered when working in two languages and demonstrates how these were overcome. This is highly topical because in recent years cross-language qualitative research has become increasingly popular, although there is little literature that explores these issues from a grounded theory perspective. The issues encountered during translation in grounded theory studies are so great that if they are neglected or mismanaged, they can have a direct impact on the validity of the research itself.

Implicit in Glaser's method is an assumption that all researchers fully understand the language being spoken, which is not necessarily the case when research is being conducted in a foreign language. We challenge this assumption by arguing that translation considerably aids the grounded theory methodology by providing extra levels of constant comparison, via the use of verbal memoing, audio recording, and working simultaneously in multiple languages during the coding phase. Hence, our paper adds considerably to grounded theory methodology and offers guidance to future researchers.
\end{abstract}

\section{Keywords:}

Grounded theory; translation; Greek; English 


\section{Translation issues in Grounded Theory}

\section{INTRODUCTION}

This paper has arisen from our experiences of using grounded theory to study the Hellenic health sector. Nurses working in hospitals and in GP practices were interviewed in Greek (in Greece) to explore the pressures they are feeling and the reasons for this. One author is fluent in both Greek and English, whereas the other is learning Greek at night school but is fluent in English. Hence, Greek was the language of the data, but English was the language of analysis due to the composition of the research team and for ease of understanding. Thus, there was a need to translate the data into English, and this led to a number of practical and methodological issues. These are the issues that our paper will explore. The findings of the 'main' grounded theory study will be published separately.

Our research is highly topical because in recent years cross-language qualitative research has become increasingly popular (Fersch, 2013). However, there are relatively few academic works about the difficulties encountered when translating Greek to English in a management context. Most works tend to focus on translating ancient Greek texts in the context of theatre (eg Hardwick, 2013; Wiles, 2007) or Biblical studies (eg White, 2009). This is surprising, because translation can be a problem area for researchers conducting qualitative studies in languages other than English who intend to publish the results in an English-language management journal (Nurjannah, Mills, Park and Usher, 2014; van Nes, Abma, Jonsson and Deeg 2010), and these issues are so great that if they are neglected or mismanaged, they can have a direct impact on the validity of the research itself (Birbilli, 2000; Temple, 2005). Indeed, Kelly and Zetzsche (2012) provide several examples of translation errors that led variously to amusement, embarrassment, and in one medical 
case, a successful lawsuit of $\$ 71 \mathrm{~m}$. In each case, misunderstanding the sense of the original phrase resulted in the error. Moreover, flawed translation processes may lead to a loss of key data (van Nes et al., 2010), or culturally-important nuances may be lost (Im et al., 2016; Venuti, 1995). Because understanding 'meaning' is essential to GT (Glaser, 1978), if these translation effects change the meaning of the data (Temple and Young, 2004), this fundamentally affects the foundations of the study itself (Al-Amer, Ramjan and Glew, 2016).

Many authors have made recommendations about the use of translation within qualitative research (see for instance Bradby, 2002; Chen \& Boore, 2009; Fenna, Tineke and Hans, 2010; Xian, 2008), but there are few studies of the translation issues that specifically arise in grounded theory (GT) research. Some literature contains the phrase 'Grounded Theory' in its title, but does not actually relate to 'doing' GT. For instance, Tarozzi (2013) explores how the translation into Italian of Glaser and Strauss' (1967) seminal work, 'Discovery of Grounded Theory', has parallels with GT principles, whereas Wehrmeyer (2014) seeks to incorporate the principles of GT into translation studies, but does not actually conduct a GT study. Nübold et al. (2017) adopt a GT methodology that combines English and German data, but the bulk of their paper focuses on the products of the study rather than a detailed discussion of the processes involved in collecting and analysing multilingual data. In none of these cases do the authors explore how to 'do' translation-focused GT research.

One notable exception to the lack of research in this area is the work of Nurjannah et al. (2014), which specifically provides a worked example of the process of data analysis in grounded theory when translation is required. However, their research follows the Straussian version of GT, not the Glaserian variant used in the present study. This is important because the two variants are very 
different. Similarly, previous research has explored issues arising from translating into English from a range of languages including Cantonese (Wong and Poon, 2010), Indonesian (Nurjannah et al., 2014), Punjabi (Bradby, 2002), and Italian (Tarozzi, 2013). To date, there is little research into translation into English from Greek in qualitative management studies. More specifically, there is also a paucity of research into the problems encountered when Greek translation is required in a Glaserian GT study. There are some signs that this may be beginning to change; for instance, the forthcoming international IATIS conference hosts a stream entitled 'Grounded Theory in Translation Studies' (IATIS, 2018). This gives support to our contention that translation is of increasing importance.

This paper is important for several reasons. Firstly, as shown above, this paper is highly topical. Secondly, it explores the use of verbal memoing within GT, and in so doing it answers a previous call for research (Stocker and Close, 2013) and provides a significant extension to theory. Thirdly, it challenges the idea that research is inhibited by recording of participant data (Glaser, 1998), which assumes that the spoken language is fully understood by all members of the research team. On the contrary, we show that recording actually enhances the research because it allows all researchers to be fully involved and hence, increases openness and creativity. Fourthly, our paper demonstrates that translation and interpretation can significantly strengthen the GT process of constant comparison, because translation forces the researcher to wrestle with the data and thereby gain a deep understanding of it. Finally, whereas Tarozzi (2013) conceptually explores translation issues within GT, the impact of translation within Glaserian GT is under-researched, and our paper therefore adds considerably to knowledge. 
This study is an appropriate topic for the research methods division of the Academy of Management (AoM) conference, since related papers have previously been presented which have explored both grounded theory (e.g. Locke and Dabu, 2014) and translation (e.g. Goeddeke, Jamyian, Chuluunbaatar and Ganbaatar, 2013). Hence, this paper continues the debates in these areas. Moreover, AoM has a long history of publishing work related to grounded theory (see for instance Browning, Beyer and Shetler, 1995; Gersick, 1988 Isabella, 1990; Sonenshein, 2014; Suddaby, 2006) and translation-based research (see for instance Ansari, Fiss and Zajac, 2010; Liang, Farh and Farh, 2012; Ou, Seo, Choi and Hom, 2017; and Zhang, Wang and Shi, 2012).

Throughout this paper, we have provided illustrative examples of translations from our study, because this is necessary if the translation process is to be understood, and for readers to make an informed judgement about the research (Birbilli, 2000; Wong and Poon, 2010). We begin our paper by briefly outlining the dual contexts of the Greek health service and GT - particularly Glaserian GT. The bulk of the paper is devoted to a worked example of how translation was used within our study, and we conclude by summarising the key theoretical contributions from this study.

\section{CONTEXT: GREEK HEALTH SERVICE}

The Greek national health service is a universal health care system provided through national health insurance and private health care. It consists of primary care (GP practices), which aims to prevent and treat illnesses, and secondary care (hospitals) which give aid via hospitalisation. The situation has deteriorated since 2011 due to austerity and hospitals are now experiencing severe 
problems (Daley, 2011; Mason, 2012). According to a major study by POEDIN (ПOEAHN - the Panhellenic Federation of Employees at Public Hospitals), the Greek health system is in a state of dissolution. The study highlights a lack of beds and medical equipment, the closure of intensive care units and operating theatres, and a national shortage of doctors and staff - in some places, $40 \%$ of medical positions are vacant (Giannakos and Papanastasis, 2016). Moreover, government health spending has fallen significantly and Greece owes $\$ 1.2$ billion dollars to pharmaceutical companies (Kottasova, 2015).

Our main study sought to explore the main concerns of nursing staff in this context, and the details will be published separately. This paper focuses on the translation issues we experienced during the study.

\section{THE NATURE OF GROUNDED THEORY (GT)}

Whilst this paper is primarily focused on the role of translation in Grounded Theory (GT) rather than the GT study itself, it is helpful to provide the reader with an outline of the methodology to help to explain what follows later in the discussion. GT aims to discover an explanatory theory of social processes (Glaser and Strauss, 1967), studied in their natural contexts (Douglas, 2005). The word 'discover' is crucial, because it implies that the theory already exists in the data: the researcher's job is to identify it (Locke, 2001). Hence, GT research does not start with a theory to prove or disprove (Glaser, 1978). Instead, the theory emerges naturally from the data (Charmaz, 1995; Glaser and Strauss, 1967). Within this broad description, there are several different approaches, for instance 'Glaserian’ (Glaser, 1978; 1998; Glaser and Strauss, 1967), 'Straussian' (Corbin and Strauss, 2008; Strauss and Corbin, 1990; 1998), Constructivist GT (Charmaz, 2000; 
2006) and Situational Analysis (Clarke, 2005; Clarke and Friese, 2007). Each version has its own supporters, and none is 'better' than the others. We therefore had to choose which version to adopt, and we chose the Glaserian variant because it is truest to the original intention of the methodology.

Glaserian GT consists of four stages: coding, memoing, sorting, and writing (Glaser and Strauss, 1967). Data are obtained, coded, then grouped into categories. It should be noted that, in practice, these four stages are not linear and that the activities normally overlap as part of an iterative process (Pandit, 1996). Memoing is fundamental to GT. The writing of memos throughout the process allows key ideas to be captured, and helps to shape the development of the emerging theory (Glaser, 1978). The fact that memos are written is significant (Glaser, 1978. 1998). Our study extends this to also include verbal memos. Although some authors have attempted this before (eg Stocker and Close, 2013), this has been done so that the researcher's thoughts were not forgotten. We used verbal memoing for a different purpose - to aid in translation and interpretation - and this therefore adds to the constant comparison process (Glaser and Strauss, 1967). Indeed, the constant comparison process is key to GT, where the emerging theory is developed through constant comparison of the data, codes, and categories. The result of this detailed line-by-line or incident-by incident constant comparative microanalysis is a dense, rich theory that "gives a feeling that nothing [has been] left out" (Glaser 1978: 58).

\section{THE NATURE OF TRANSLATION AND INTERPRETATION}

Translation and interpretation are related concepts in linguistic studies. The former is related to written messages, whereas the latter is related to the spoken word (Bell, 1991). In the present 
study, we were involved in both aspects. In the field, we were interacting directly with participants, and hence real-time interpretation from Greek to English was necessary for the English-speaking author to be able to follow the conversations. Discussions were transcribed into Greek text and then translation of these into English was the foundation for the constant comparison process. Hence, translation, rather than interpretation, is the area that receives the greatest emphasis in this paper.

It is important to note that any act of communication involves translation - if only to process meaning. Steiner (1995) argues that this means that translation is both inter-lingual (within the same language) and intra-lingual (between different languages). Intra-language translation is, therefore, the most common form of communication. An extreme example of this is an English dictionary, which translates English words into other English words, but there are less obvious examples where one word has multiple meanings. For instance, as Weaver (1955) observes, the English word 'fast' has several meanings - two of which are effectively opposites ('rapid' and 'motionless') - and therefore to understand the word it is necessary to read the words around it to get a conception of the sense that was intended. This issue is magnified when translating from one language into another.

Nida (1976) classifies translation theories into three categories, or 'turns' - linguistic, philological, sociolinguistic. Linguistic emphasises the structural difference between the source and target languages; philological emphasises the words themselves; and sociolinguistic emphasises the meanings, cultural norms, and contexts inherent within the communication process. The present GT study fits into the sociological turn, because we were not only working with linguistic meaning but also considered factors such as the context of what was said, the setting in which translation 
took place, and the translator's own knowledge (As-Safi, 2011). Hence, our focus was on the intended meaning, or the sense, of the text rather than a literal translation.

It is important that researchers address potential translation issues prior to data collection and analysis to ensure that the meaning of the data is not lost during the process of translation (Fenna et al., 2010; van Nes et al., 2010). As indicated above, Nurjannah et al. (2014) provide a worked example of a translation-based GT study and offer recommendations to guide future researchers. However, they adopt a Straussian approach to GT, whereas our study follows a Glaserian approach. The two methods differ considerably in places, including in the constant comparison aspect, and hence Nurjannah et al.'s (2014) study was of conceptual, rather than practical, relevance to our study.

Having discussed these ideas in principle, the remainder of this paper explores in more detail what happened in the present study and implications for theory and practice.

\section{THE USE OF TRANSLATION IN THE PRESENT STUDY}

The following pages discuss the process of data collection, interpretation, and translation. These are presented separately for clarity and to aid the reader's understanding of what happened, but the reality was different. Interpretation was carried out during the data collection phase, allowing for verbal memoing to occur (Stocker and Close, 2013) while translation took place after data collection, and therefore its position is accurately presented below. For reasons of clarity and brevity, the Greek-speaking author and the English-speaking author are described below as Author 1 and Author 2 respectively. 


\section{Data collection}

Prior to each interview, we had identified themes that had arisen from previous interviews via a constant comparison approach, which was aided by translation and by verbal memoing (Stocker and Close, 2013) (see below) which was obtained during interpretation. Consequently, the themes that emerged allowed Author 2 to help to frame the direction of the early stages of the research. Participants were contacted several weeks before the interview to ensure they were willing to contribute, and neutral venues were found for the interviews where it was possible for them to speak freely and candidly.

It was clear from the outset that data collection would presents difficulties because the Englishspeaking author did not have the necessary linguistic skills. We faced a dilemma. Should the interviews be conducted in English or in Greek? The consensus in the literature is that data must be gathered in the local language (Nübold et al., 2017; Nurjannah et al., 2014), but nevertheless, English offered several advantages. Firstly, we are both fluent in English, and most participants could be expected to have some knowledge of the language. Secondly, it was intended that the research would be published for an English-speaking audience and therefore this approach would negate the need for lengthy translation. Thirdly, if the data had been collected in English from participants who were not totally fluent in the language they might have used the words that were most important to them, rather than correct grammar, and this might have revealed important clues about their underlying thought processes (Xian, 2008).

However, there were also several counter-arguments. We sought to understand the culture and lived experiences of participants, and this might be diluted by forcing participants to speak in what was to them a foreign language. Moreover, participants whose English was weak might feel 
uncomfortable, and we sought to avoid this at all costs. It might also impact upon the data, because participants' translations might mask underlying issues by 'sanitising' the content by forcing the issue to be discussed in words that participants knew, rather than by expressing themselves freely. With the intention of allowing participants to be in control throughout (Robson, 2002; Saunders, Lewis and Thornhill, 2012), we asked them what they would prefer, and on every occasion, it was clear that they preferred to speak in Greek. Thus, each interview was conducted in Greek for the benefit of both the data quality and participants, even though we knew this would present us with practical problems.

Although Glaser (1998) argues against recording, we recorded all interviews on a Dictaphone with the prior consent of the participants. There were several reasons for this. Many of these are obvious, such as providing a permanent record, capturing the maximum amount of data, and offering us a chance to revisit the data as and when desired. The audios could be listened to many times, and this allowed a fuller understanding of participants' concerns to be obtained, because repeated listening identified new avenues to be explored as the meaning gradually became clear. The tapes could also be transcribed to provide a written source of data, and these transcriptions formed the basis of later translations. Very importantly, however, this allowed Author 1 to interpret for the other author (see below) without the need for her to take detailed notes, and allowed her to take a full and interactive part without the additional cognitive burden of extensive writing, and led to the creation of verbal memos which contributed to the constant comparison approach. Recording conversations was therefore a crucial component of our GT approach, despite Glaser's objections. Many other researchers have successfully used this technique in GT studies (see for instance Frost, 2004; Munkejord, 2009; Musselwhite and Haddad, 2010), although translation and verbal memoing were not part of these studies. 
Although Glaser (1978) recommends against taking notes during GT interviews, we often had to gather data from several people within a short period and had to make some notes at the time in order not to forget key data and to ensure that the right notes referred to the right situation. Moreover, notes helped us to keep track of our emerging thinking and were often informal memos that helped to guide our thoughts (Glaser, 1978). Despite Glaser's (1978) objections, Lings and Lundell (2005) argue that note taking is common among GT researchers, and this gave us some comfort that we were not completely diverging from recommended practice.

Twenty-six interviews were conducted. As noted above, the purpose of this paper is to document and analyse the translation issues that we encountered. The findings of our study will be published separately.

\section{Interpretation}

This discussion is not intended to mislead the reader into thinking that interpretation was divorced from data collection. In reality, the two phases were interwoven. This section is presented separately purely for reasons of clarity.

During the interviews, most of the questioning was done by Author 1, and as answers were received, she interpreted these for the benefit of the second author. This was done discretely to minimise disruption for participants. These were verbal memos (see below), which helped the constant comparison process Author 1 interpreted the 'gist' of the conversation without worrying about literal or grammatical accuracy - that would come from the translation from the transcript, which later took place and together with the verbal memos, enhanced the constant comparison process. An example of this occurred after a long section of speech when Author 1 stated that 
"she's talking about why doctors are leaving the hospital" - this is effectively a summary of the participant's statement. This therefore follows Ivir's $(1987 ; 2004)$ substitution strategy (see below). This allowed the second author to contribute directly because he could then pose questions. Author 1 then interpreted these back into Greek for the participants.

In GT, a fundamental requirement is that authors make notes (called 'memos') to aid their thinking, to summarise, to generate and collect ideas, and so on (Glaser and Stauss, 1967). These are written and formally documented (Glaser, 1978). We wrote many formal memos during the study. However, Author 1's interpreted summaries, and Author 2's subsequent comments can frequently be heard clearly on the audio recording, and these also appear in the transcriptions. These are, effectively, verbal GT memos which can add an instant 'gut feeling' insight (Stocker and Close, 2013) that helps to explain what is happening in the data (Glaser, 1978), and can spark the recall of situational aspects, initial thoughts, and overarching context which perhaps remains unsaid in the actual interviews (Stocker and Close, 2013). This is important because the brain processes verbal and written thoughts separately (Michael, Keller, Carpenter, and Just, 2001), and hence they complement, rather than replace, traditional written memos.

\section{Translation}

Having collected and transcribed the data, the issue then was its translation into English. There are three main questions: Who should translate? When should translation be undertaken? How should translation be undertaken? It is obvious that the translation must be performed by someone who is fluent in the language (Nurjannah et al., 2014), but it is also essential that the translator is directly involved with the research so that he or she can clarify terms and concepts that would otherwise remain ambiguous or decontextualised (Tarozzi, 2013). This also helps to ensure that participants' 
intended meanings are preserved - particularly when culturally-or-contextually specific phrases are used (Nurjannah et al., 2014). For these reasons, in the present study, the translator was Author 1. The merging of two languages and cultures formed the translator's habitus (our way of representing ourselves to others - Bourdieu, 1977), and through translation and interpretation the information transmitted was therefore more easily understood by Author 2 .

There was a danger that this habitus might have led to a power imbalance (Bourdieu, 1991; Nurjannah et al., 2014) within the research team with the bilingual researcher having an apparent monopoly in interpreting the research findings, but this was not the case in the present study, because as suggested by Lesch (1999), we consciously balanced out the power relationships by emphasising the need for communication. Firstly, we shared the workload (Svetlana, 2007). Secondly, the second researcher was present at all interviews and was made to feel an important part of the team. His Greek skills were not zero, and on occasion he could contribute meaningfully to the questioning. More importantly, his independence from the host culture was actually positive because he was able to ask the 'obvious' questions that might otherwise have been overlooked due to the first researcher's familiarity with the context. This meant that taken-for-granted assumptions were questioned (Starks and Brown Trinidad, 2007), and we were both fully involved in the analysis. Finally, the second researcher was considerably more experienced in GT and could bring this expertise to bear on the study, and this helped to offset any hypothetical imbalance within the team. The close involvement of both authors throughout the whole process was effectively a form of reflective practice, which safeguarded the process and the participants against a power imbalance. Indeed, it could be argued that the main objective of translation and interpretation is the attempt to balance out the power relationship (Bourdieu, 1991). 
In GT studies, there is no single version of the 'truth' and a technically accurate translation may not convey the intent behind the words (Bradby, 2002). This is another reason why translation within GT naturally belongs in the sociological approach, since each communication is subject to different interpretations depending upon cultural and sociological factors. Although it would have been possible to employ formal translation models, we chose not to do this because as Author 1 is bilingual, it was possible to translate the source text with minimal difficulty. It is beyond the scope of this this paper to explore the merits and demerits of the various models that have been used for translation studies (but see Wehrmeyer, 2014 for an overview of the topic).

Having discussed who should translate, the next issue was when the translation should be carried out. Should the translation be done immediately after data transcription, should it be done during the analysis, or should it be done immediately prior to writing up the research for publication? There is no consensus in the literature. Nübold et al. (2017) suggest that the original language should be used for as long as possible, and that translation should take place once the analysis has been completed. Suh, Kagan and Strumpf (2009) suggest that translation should occur during the analysis phase. In the present study, although Larkin, de Casterlé and Schotsmans (2007) argue against translation before analysis, because this runs the risk of losing the participants' intended meaning it was clear that the only realistic option was to translate immediately after transcription and before the analysis began - a view supported by Nurjannah et al. (2014). Only one author could confidently understand the Greek data, and delaying the translation until the end would have effectively side-lined the other. Moreover, Glaser (1998) suggests that constant comparison is the key difference between GT and other methodologies. Translation at the end undermines this, because Author 2 would literally have nothing to compare until the end of the process, and 
therefore the authors would not be being faithful to the methodology which they wished to avoid at all costs.

The 'who' and 'when' questions had therefore been settled. The final question was how should translation be undertaken? Equivalence, or faithfulness, is a key tenet of translation studies. Essentially, this seeks to ensure that the translated text is similar to the original text. There are many types of equivalence including dynamic equivalence, where the meaning of the source language and target language are as close as possible (Venuti, 2012; Nida and Taber, 1969), and formal equivalence, where the content in the source language matches the content in the target language as closely as possible (Baker and Saldanha, 2009). Baker and Saldanha (2009) argue that over the past few decades, there has been a movement away from an emphasis on equivalence and faithfulness, towards a greater appreciation of the purpose and function of the text in the original culture. Indeed, in the present study, many statements made in Greek by participants had no equivalent translation in English.

This provides further support for locating this paper within translation's sociological turn. These issues can be illustrated by a simple example from Greek. The phrase ' $\sigma \eta \dot{\eta} \mu \varepsilon \rho \alpha \kappa \alpha \dot{v \varepsilon \imath ~ \zeta \varepsilon ́ \sigma \tau \eta ’ ~ m e a n s ~}$ 'it's hot today', but a more literal translation is 'today does heat'. Hence, Derrida (1998) argues that translation can say almost the same thing as the original, and indeed, these results show the lack of a single 'correct' answer (Temple, 2005; Tarozzi, 2013) and highlight the difficulty the authors faced. Consequently, translation is always an interpretive act and is always laden with social and cultural connotations, hence it can never be an objective and neutral process (van Nes et al., 2010; Wong and Poon, 2010). 
There are many factors which can affect the 'equivalence', or 'faithfulness' of translation, such as the linguistic abilities of the translator and the circumstances in which the translation takes place (Birbilli, 2000). Neither author has any training in translation and therefore both lack linguistic abilities to some extent, although Author 1 is much more fluent in Greek than the other, and is likely to provide 'accurate' translation. However, even if the translation is 'accurate', it does not necessarily convey the meaning behind the words (Croot, Lees and Grant, 2011) and it does not take account of cultural or contextual differences (Su \& Parham, 2002). Moreover, linguistic equivalence may not always be achievable (Wehrmeyer, 2014). For instance, the English expression "it's raining cats and dogs" cannot easily be understood by someone who does not share a common cultural background, even if they speak English well (Tarozzi, 2013).

Early in the process, we wished to satisfy ourselves as to the 'equivalence' of the translations made up to this point. For instance, it was possible that another Greek speaker from a different part of the country might assign a different meaning to the text. Hence, samples of interview translations were forwarded to Author 2's Greek tutor, and she provided her own translations without sight of the originals, and a then comparison was made. Three representative examples are provided in Table 1, where a selection of participants' statements have been translated into English in two ways: a translation by Author 1, and another translation by Author 2's Greek tutor.

Insert Table 1 about here 
These examples show several things. In each case, the tutor's translation and Author 1's translation were very similar, although not identical. Although some nuances may have been lost in translation (Im et al., 2016), the essential meaning was the same. This was vitally important in this study (Al-Amer et al., 2016), and was particularly true given the GT methodology, where understanding the meaning is much more important than accurately recording direct quotations (Glaser, 1998). Secondly, it is common for a translation to contain a mix of approaches (Baker, 2011), and in this case, both translators followed three of Ivir's $(1987$; 2004) seven strategies translation by omission, literal translation, and translation by substitution.

Translation by omission occurs when the source text contains phrases that phrases that are not important to the meaning (Baker, 2011). This can be seen in the second example: both translations ignored the phrase ' $\rho \varepsilon \pi \alpha l \delta i i^{\mu} \mu v^{\prime}$ ('my child'), which occurs twice, because the translators knew this to be a phrase that is in common use, but which is somewhat meaningless and which reflects cultural contexts (Angelelli, 2003). Similar examples are found in English, such as 'like' in the phrase 'it was, like, an exciting game'. Literal translation is an 'exact' or faithful translation from the source language to the target language (Molina and Hurtado Albir, 2002) and can be seen in both examples where Greek words have been directly converted into the English equivalent, for

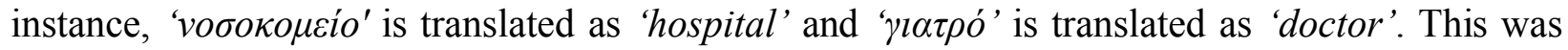
done by both translators. Substitution occurs when translators use a similar phrase rather than an exact phrase in order to render the phrase less strange (Baker, 2011). For instance, in the third examples, a literal translation might be 'you say you play the duck'. This is a common Greek idiom that has no literal meaning in English. Hence, both translators substituted this with a more naturalsounding English equivalent, but not a literal, phrase. 
It should be remembered that neither of us nor the Greek tutor has any training in translation, and all were completely unaware that they were following Ivir's strategies. They indicated that they translated the text in the way that 'felt right' to them.

\section{Translation in the process of coding}

Given the importance of coding within the GT analytical process (Glaser and Strauss, 1967), an important question was 'which language should be used for coding?' When other researchers have used dual-language coding, sometimes the results were very similar in both languages (Chen and Boore, 2009 - English and Chinese), whereas sometimes there were some slight differences between the codes generated in the two languages (Nurjannah et al., 2014 - English and Indonesian). This may be due to the different characteristics of the languages concerned (Nurjannah et al., 2014).

Whereas in the study by Nurjannah et al. (2014) the translated interviews were coded in English by the bilingual researcher, in the present case we were aware of benefits of retaining the original language too. Hence, a dual approach was taken. The data were coded in English by Author 2 and were coded in Greek by Author 1. Coding took place as soon as possible after the interviews. This approach proved very beneficial, because the latter could take full account of the context in which the comments were made and the English researcher was able to code irrespective of context - or at least, without the same level of knowledge. When the English and Greek codes were compared, this often raised hitherto unexpected lines of enquiry. For instance, Author 1 coded a section of speech as ' $\tau \varepsilon \mu \pi \varepsilon ́ \lambda \eta \varsigma$ ' (lazy) and Author 2 coded the same extract as 'disinterested'. This led to a detailed discussion between us which opened up new lines of enquiry, because it was important to identify the 'proper' interpretation which was resolved in follow-up interviews with participants. 
Therefore, working in two languages considerably strengthened the GT process because it added an extra layer of rigour to the constant comparison process.

Throughout the study, memoing was done in English following research team discussions. Data, codes, and memos were constantly compared in English, and the results guided the ongoing interview process. Periodically, memos were sorted to try to develop the emerging theory. As new ideas emerged during sorting, these were themselves recorded in memos (Glaser, 1978). These memos were arranged in the sequence which best allowed the theory to be described (Glaser and Strauss, 1967). Sorting was therefore an iterative process which gradually refined the theory.

\section{Translation of the literature in the present study}

We used two main sources of literature in this study. All context-related literature was in Greek, whereas all theoretical literature was in English. Because all theoretical literature was in English, no translation was required, other than intra-language (i.e. English-English) translation when topics were outside our own expertise, such as medical terms and the translation literature. This was not problematic. we read and re-read paragraphs of text and paraphrased these into terms that we could relate to.

Greek literature was focused on the Hellenic health service and included procedure notes, internal memoranda, newspaper articles, etc, and we translated these as described above. There were also several television programmes that were of interest. Some of these included interviews with medical staff or hospital directors, and these were dealt with in the same way as our empirical interview data - i.e. they were transcribed, and were then translated. This is another reason why we opted for the early translation of the empirical data. In this way, all the data (empirical and 
literature) was in the same language and this simplified the constant comparison process and made visible relationships between the data and the literature that might otherwise have been obscured. This ensured that we remained true to the GT methodology.

\section{CONCLUSIONS AND IMPLICATIONS}

Stocker and Close (2013) explore the use of verbal memoing within GT, which they recommend to other researchers. However, they argue that further research is required to determine whether recording can enhance other parts of the research process. Our paper answers this call, and has found that recording can benefit in GT translation studies because expressing 'instant interpretations' can help non-native researchers to be more fully involved in the data collection and analysis processes. Hence, this enhances conceptualisation and adds an extra layer to the constant comparison process because all researchers can immediately get close to the data, which is a key tenet of GT (Glaser, 1978; 1998).

Although recording has been successfully used in many previous GT studies (e.g. Munkejord, 2009; Musselwhite and Haddad, 2010), in order to conduct Glaserian GT, researchers are expressly instructed not to record interviews, because this can impact on what participants choose to reveal, and it damages researchers' creativity (Glaser, 1998). We accept this, but argue that there is a hidden assumption - that all researchers fully understand the language being spoken. This assumption does not take into account potential cross-cultural research partnerships which may be formed as part of an increasingly global research community. Hence, our paper challenges this assumption and concludes that recording may prove to be necessary in some circumstances, such 
as when there are non-native speakers in the research team. Moreover, our experience was that having different cultures and different linguistic abilities within the research team considerably enhanced creativity as ideas were discussed, and this vastly outweighed the loss of creativity identified by Glaser. Hence, despite Glaser's (1978) objections, this study encourages the use of audio recording in translation-based GT studies.

Furthermore, we argue that using translation and interpretation significantly strengthens the GT process of constant comparison, because translation forces the researcher to wrestle with the data and thereby gain a deep understanding of it. Translation is effectively another extra layer in the process because comparison happens twice: once during the translation when meaning is being sought, and once the data have been translated when patterns and themes are being discovered across many data sources. Glaser's oft-quoted maxim 'all is data' implicitly requires that the data must be understandable for it to be potentially useful. If the data cannot be understood by the researchers, then theories cannot emerge from it. Hence 'all is not data' if some data are being excluded from the research. Translation helps to make visible this otherwise hidden data. Although Tarozzi (2013) conceptually explores translation issues within GT, the impact of translation within Glaserian GT has not been empirically studied before, and this paper therefore adds considerably to knowledge.

Our research is therefore significant and highly topical because in recent years cross-language qualitative research has become increasingly popular (Fersch, 2013; Xian, 2008). The importance of the topic can be seen from the fact that the international IATIS conference in 2018 has a stream entitled 'Grounded Theory in Translation Studies'. This supports our contention that translation is of increasing importance, and hence our paper is both important and topical. Our paper seeks to 
Submission number: 10336

be at the forefront of this debate, and by sharing our experiences with other scholars, we hope to spark further research in this new and exciting area, and it will be interesting to observe developments in the coming years. 
Submission number: 10336

\section{References}

Al-Amer, R., Ramjan, L., Glew, P., Darwish, M. \& Salamonson, Y. 2016. Language translation challenges with Arabic speakers participating in qualitative research studies. International Journal of Nursing Studies, 54: 150-157.

Angelelli, C. 2003. The interpersonal role of the interpreter in cross-cultural communication. In L. Brunette, G.L. Bastin, I. Hemlin, \& H. Clarke (eds). Critical Link 3: Interpreters in the community : 15-26. Amsterdam: John Benjamins

Ansari, S.M., Fiss, P.C. and Zajac, E.J., 2010. Made to fit: How practices vary as they diffuse. Academy of Management Review, 35(1): 67-92.

As-Safi, A. B. 2011. Translation Theories: Strategies and Basic Theoretical Issues. Petra University: Amman

Baker, M. 2011. In other words: A coursebook on translation (2nd edn). Abingdon: Routledge.

Baker, M. \& Saldanha, G. 2009. The Routledge Encyclopaedia of Translation Studies (2nd edn). Abingdon: Routledge.

Bell, R. T. 1991. Translation theory: where are we going? META, 31(4): 403-415.

Birbili M. 2000. Translating from one language to another. Social Research Update, 31. University of Surrey. Retrieved 05/04/17 from http://sru.soc.surrey.ac.uk/SRU31.html

Bourdieu, P. 1977. Outline of a Theory of Practice (tr. Nice, R.). Cambridge: Cambridge University Press.

Bourdieu, P. 1991. Language and symbolic power. Harvard: Harvard University Press.

Bradby, H. 2002, Translating culture and language: a research note on multilingual settings. Sociology of Health \& Illness, 24(6): 842-855.

Browning, L. D., Beyer, J.M. and Shetler, J.C. 1995. Building cooperation in a competitive industry: SEMAT-ECH and the semiconductor industry. Academy of Management Journal, 38: 113-151.

Charmaz, K. 1995. Grounded theory. In J. A. Smith, R. Harre \& L. Van Langenhove (Eds.), Rethinking Methods in Psychology: 27-49. London: Sage

Charmaz, K. 2000. Grounded Theory: Objectivist and Constructivist Methods. In N. K. Denzin \& Y. S. Lincoln (eds.) Handbook of Qualitative Research (2 ${ }^{\text {nd }}$ edn) :509-535Thousand Oaks, CA: Sage.

Charmaz, K. 2006. Constructing Grounded Theory. London: Sage. 
Chen, H. Y., \& Boore, J. R. P. 2009. Translation and back-translation in qualitative nursing research: Methodological review. Journal of Clinical Nursing, 19(1-2): 234-239

Clarke, A. E. 2005. Situational Analysis: Grounded Theory after the postmodern turn. Thousand Oaks, CA: Sage.

Clarke, A. E. \& Friese, C. 2007. Situational Analysis: Going Beyond Traditional Grounded Theory. In K. Charmaz \& A. Bryant (Eds.), Handbook of Grounded Theory: 694-743. London: Sage.

Corbin, J. \& Strauss, A. L. 2008. Basics of Qualitative Research (3rd edn). Thousand Oaks, CA: Sage.

Croot, E. J., Lees, J., \& Grant, G. 2011. Evaluating standards in cross-language research: A critique of Squires' criteria. International Journal of Nursing Studies, 48: 1002-1011.

Daley, S. 2011. "Fiscal Crisis Takes Toll on Health of Greeks". The New York Times. 12/27/2011. Accessed 9/12//2017. http://www.nytimes.com/2011/12/27/world/europe/greeks-reeling-fromhealth-care-cutbacks.html

Derrida, J. 1998. Monolingualism of the other, or the prosthesis of origin. Stanford, CA: Stanford University Press.

Douglas, D. 2005. The human complexities of entrepreneurial decision-making: a grounded case considered. International Journal of Entrepreneurial Behaviour and Research, 11(6): 422435.

Fenna, V. N., Tineke, A., Hans, J., \& Dorly, D. 2010. Language differences in qualitative research: Is meaning lost in translation? European Journal of Ageing, 7: 313-316.

Fersch, B. 2013. Meaning: lost, found or 'made' in translation? A hermeneutical approach to crosslanguage interview research. Qualitative Studies, 4(2): 86-99.

Frost, A. 2004. Therapeutic engagement styles of child sexual offenders in a group treatment program: A grounded theory study. Sexual abuse, 16(3):191-208.

Gersick, C.J.G. 1988. Time and transition in work teams: toward a new model in group development. Academy of Management Journal, 31: 9-41.

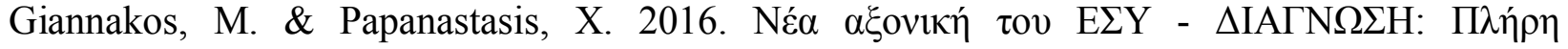

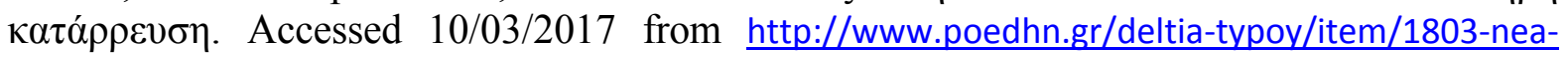
aksoniki-tou-esy---diagnosi-pliri-katarrefsi

Glaser, B. G. 1978. Theoretical sensitivity: Advances in the methodology of grounded theory. Mill Valley, CA: Sociology Press. 
Submission number: 10336

Glaser, B. G. 1992. Basics of grounded theory analysis: emergence vs forcing. Mill Valley, CA: Sociology Press.

Glaser, B. G. 1998, Doing Grounded Theory: Issues and Discussions. Mill Valley, CA: Sociology Press.

Glaser, B. G \& Strauss, A. L. 1967. The discovery of grounded theory: strategies for qualitative research. Chicago: Aldine.

Goeddeke, F. X., Jamyian, D., Chuluunbaatar, E. \& Ganbaatar, U. 2013. Validation of the committee skill translation method. Academy of Management Proceedings 2013:1:1566 doi: 10.5465/AMBPP.2013.15666abstract

Hardwick, L. 2013. Translating Greek plays for the theatre today. Target. International Journal of Translation Studies, 25: 321-342.

IATIS 2018. International Association for Translation and Intercultural Studies: IATIS 6th International Conference. Accessed 16th July 2017 from: https://www.iatis.org/index.php/6th-conference-hong-kong-2018/item/1459-panels\#Panel02

Im, E.O., Kim, S., Tsai, H.M., Nishigaki, M., Yeo, S.A., Chee, W., Chee, E. \& Mao, J.J. 2016. Practical issues in multi-lingual research. International Journal of Nursing Studies, 54 :141149.

Isabella, L. A. 1990. Evolving interpretations as change unfolds: How managers construe key organizational events. Academy of Management Journal, 33: 7-41.

Ivir, V. 1987. Procedures and Strategies for the Translation of Culture. In G. Toury (ed.), Translation Across Cultures :35-46. New Delhi: Bahri Publications.

Ivir, V. 2004. Translation of culture and culture of translation. Studia romanica et anglica Zagrabiensia, 47, :117-126.

Kelly, N. \& Zetzsche, J. 2012 Found in Translation: How Language Shapes Our Lives and Transforms the World. New York, NY: Perigee Books.

Kottasova, I. 2015. Inside Greece's health care crisis. Accessed 10/03/2017 from http://money.cnn.com/2015/07/10/news/economy/greece-health-care-crisis/

Larkin, P. J., de Casterlé, B. D., \& Schotsmans, P. 2007. Multilingual translation issues in qualitative research: Reflections on a metaphorical process. Qualitative Health Research, 17: 468-476.

Lesch, H. 1999. Community translation: right or privilege. In M. Erasmus (ed.), Liaison interpreting in the community. Pretoria: Van Schaik: 90-98. 
Liang, J., Farh, C.I. and Farh, J.L., 2012. Psychological antecedents of promotive and prohibitive voice: A two-wave examination. Academy of Management Journal, 55: 71-92.

Lings, B. \& Lundell, B. 2005. On the adaptation of Grounded Theory procedures: insights from the evolution of the $2 \mathrm{G}$ method. Information Technology \& People, 18(3) :196-211.

Locke, K. 2001. Grounded Theory in Management Research. London: Sage.

Locke, K. and Dabu, A. 2014. Generating a theory in entrepreneurship: Re-envisioning concept development in grounded theory. Academy of Management Proceedings 2014:1 10509; doi: 10.5465/AMBPP.2014.10509abstract

Mason, P. 2012 "Struggling Greeks losing belief in the state". Accessed 09/12/2017 from http://www.bbc.co.uk/news/business-17067104

Michael, E. B., Keller, T. A., Carpenter, P. A., \& Just, M. A. 2001. fMRI investigation of sentence comprehension by eye and by ear: Modality fingerprints on cognitive processes. Human Brain Mapping, 13(4): 239-252.

Molina, L. \& Hurtado Albir, A. 2002. Translation techniques revisited: A dynamic and functionalist approach. Meta: Translators' Journal, 47:498-512

Munkejord, K. 2009. Methodological emotional reflexivity: The role of researcher emotions in grounded theory research. Qualitative Research in Organizations and Management: An International Journal, 4(2):151-167.

Musselwhite, C.B. \& Haddad, H. 2010. Exploring older drivers' perceptions of driving. European Journal of Ageing, 7(3):181-188.

Nida, E. A. 1976. A framework for the analysis and evaluation of theories of translation. In R. W. Brislin (ed.), Translation: applications and research. New York: Gardner Press: 47-91.

Nida, E. A. \& Taber, C. R. 1969. The Theory and Practice of Translation. Leiden: EJ Brill.

Nübold, A., Bader, J., Bozin, N., Depala, R., Eidast, H., Johannessen, E. A., \& Prinz, G. 2017. Developing a taxonomy of dark triad triggers at work-A grounded theory study protocol. Frontiers in Psychology, 8, Accessed 11/14/2007 from http://doi.org/10.3389/fpsyg.2017.00293

Nurjannah, I., Mills, J., Park, T. \& Usher, K. 2014. Conducting a grounded theory study in a language other than English: procedures for ensuring the integrity of translation. Sage Open, 4(1), $\quad$ Accessed $\quad 05 / 04 / 2017$ from http://journals.sagepub.com/doi/abs/10.1177/2158244014528920

Ou, A.Y., Seo, J.J., Choi, D. and Hom, P.W., 2017. When can humble top executives retain middle managers? The moderating role of top management team faultlines. Academy of Management Journal, 60: 1915-1931. 
Submission number: 10336

Pandit, N. R. 1996. The creation of theory: A recent application of the grounded theory method. The Qualitative Report, 2(4):1-14.

Robson, C. 2002. Real-World Research (2 ${ }^{\text {nd }}$ edn). Oxford: Blackwell.

Saunders, M., Lewis, P. \& Thornhill, A., 2012, Research Methods for Business Students (6 ${ }^{\text {th }}$ edn), Harlow: Pearson Education.

Sonenshein, S. 2014. How organizations foster the creative use of resources. Academy of Management Journal, 57: 814-848.

Starks, H. \& Brown Trinidad, S. 2007. Choose Your Method: A comparison of phenomenology, discourse analysis and grounded theory. Qualitative Health Research, 17: 1372-1380.

Steiner, G. 1995. What Is Comparative Literature? Oxford: Clarendon.

Stocker, R., \& Close, H. 2013. A novel method of enhancing grounded theory memos with voice recording. The Qualitative Report, 18(1): 1-14.

Strauss, A. L. \& Corbin, J. 1990. Basics of qualitative research: Grounded theory procedures and techniques. Newbury Park, CA: Sage.

Strauss, A. L. \& Corbin, J. 1998. Basics of qualitative research: Techniques and procedures for developing grounded theory (2nd edn.). Thousand Oaks, CA: Sage.

Su, C. T., \& Parham, L. D. 2002. Generating a valid questionnaire translation for cross-cultural use. American Journal of Occupational Therapy, 56 :581-585.

Suddaby, R. 2006. From the editors: What grounded theory is not. Academy of Management Journal, 49: 633-642.

Suh, E. E., Kagan, S., \& Strumpf, N. 2009. Cultural competence in qualitative interview methods with Asian immigrants. Journal of Transcultural Nursing, 20(2), 194-201.

Svetlana, S. 2007. Double vision uncertainty: The bilingual researcher and the ethics of crosslanguage research. Qualitative Health Research, 17: 529-538.

Tarozzi, M. 2013. Translating and Doing Grounded Theory Methodology: Intercultural Mediation as an Analytic Resource. Forum Qualitative Sozialforschung / Forum: Qualitative Social Research, 14(2), Art 6. Retrieved 05/04/2017 from http:/www.qualitativeresearch.net/index.php/fqs/article/view/1429

Temple, B. 2005. 'Nice and Tidy: Translation and Representation'. Sociological Research Online, 10(2). Retrieved 05/04/2017 from http://www.socresonline.org.uk/10/2/temple.html

Temple, B. \& Young, A. 2004. Qualitative research and translation dilemmas. Qualitative research, 4(2): 161-178. 
van Nes, F., Abma, T., Jonsson, H. \& Deeg, D. (2010). Language differences in qualitative research: is meaning lost in translation? European journal of ageing, 7(4): 313-316.

Venuti, L. 1995. The Translator's Invisibility. New York: Routledge

Venuti, L. 2012. The Translation Studies Reader (3rd edn). New York: Routledge.

Weaver, W. 1955. Translation. Machine translation of languages, 14:15-23.

Wehrmeyer, J. 2014. Introducing Grounded Theory into translation studies. Southern African Linguistics and Applied Language Studies, 32: 373-387.

White, J.R. 2009. The King James Only Controversy: Can You Trust Modern Translations? Bloomington, MN: Baker Books.

Wiles, D. (2007). Translating Greek Theatre. Theatre Journal, 59:363-366.

Wong, J.P.H. \& Poon, M.K.L. 2010 Bringing translation out of the shadows: Translation as an issue of methodological significance in cross-cultural qualitative research. Journal of Transcultural Nursing, 21(2): 151-158.

Xian, H. 2008. Lost in translation? Language, culture and the roles of translator in cross-cultural management research, Qualitative Research in Organizations and Management: An International Journal, 3(3): 231-245.

Zhang, Z., Wang, M.O. and Shi, J., 2012. Leader-follower congruence in proactive personality and work outcomes: The mediating role of leader-member exchange. Academy of Management Journal, 55: 111-130. 


\section{Table 1: Different translations from the same data source}

\begin{tabular}{|c|c|c|}
\hline $\begin{array}{c}\text { Participant's original } \\
\text { statement }\end{array}$ & Author 1's translation & $\begin{array}{c}\text { Translation from Greek } \\
\text { tutor }\end{array}$ \\
\hline 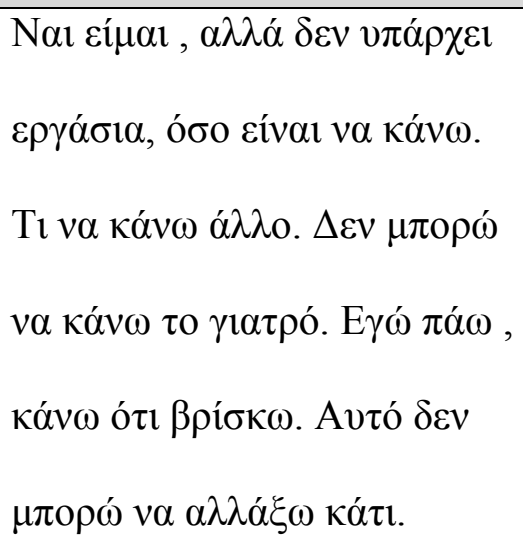 & $\begin{array}{l}\text { Yes, I am, but there is no } \\
\text { work, I do as much as I can. } \\
\text { What else can I do? I can't } \\
\text { be the doctor, I go to work, } \\
\text { do what I find. I can't } \\
\text { change anything }\end{array}$ & $\begin{array}{l}\text { Yes, I am but there are no } \\
\text { jobs, I do few things. What } \\
\text { else to do? I can't be the } \\
\text { doctor, I do whatever job I } \\
\text { find. This is the situation. I } \\
\text { can't change it. }\end{array}$ \\
\hline 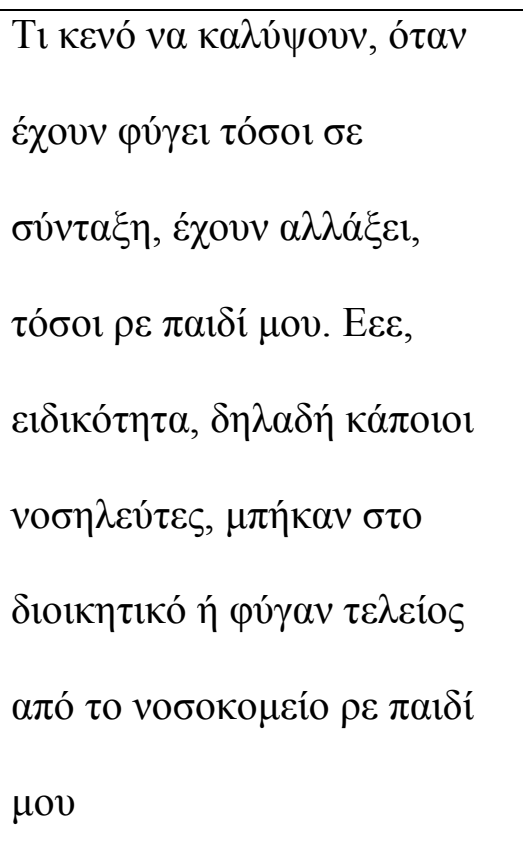 & $\begin{array}{l}\text { It is impossible to cover } \\
\text { these gaps when so many } \\
\text { people have retired, or have } \\
\text { changed specialisation. } \\
\text { Some nurses have entered } \\
\text { administration or left the } \\
\text { hospital completely }\end{array}$ & $\begin{array}{l}\text { It is impossible to cover } \\
\text { these gaps when many of } \\
\text { them have retired. In } \\
\text { specialisms, some of the } \\
\text { nurses moved to } \\
\text { administration, or they left } \\
\text { the hospital }\end{array}$ \\
\hline 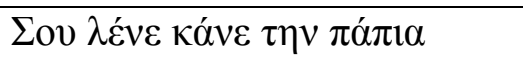 & Pretend that you don't know & Pretend you are a fool \\
\hline
\end{tabular}

